\title{
Chromosomal locations of genes related to flavonoid and anthocyanin production in leaf sheath of shallot (Allium cepa L. Aggregatum group)
}

\author{
Masayoshi Shigyo ${ }^{1, *}$, Yosuke Tashiro ${ }^{1}$, Mitsuyasu Iino ${ }^{1}$, Norihiko Terahara $^{2}$, \\ Kanji Ishimaru ${ }^{1}$, and Shiro Isshiki ${ }^{1}$ \\ ${ }^{1}$ Department of Biotechnology and Plant Breeding, Faculty of \\ Agriculture, Saga University, Saga 840, and \\ ${ }^{2}$ Department of Food Science and Technology, College of Horticulture, \\ Minami-Kyushu University, Takanabe, Miyazaki 884, Japan
}

(Received 4 June 1997, accepted 16 July 1997)

\begin{abstract}
High-performance liquid chromatography (HPLC) analyses using a series of alien monosomic addition lines (AMALs) of Japanese bunching onion (Allium fistulosum L.) having extra chromosomes from shallot (A. cepa L. Aggregatum group) were performed to determine the chromosomal locations of the genes for flavonoid and anthocyanin production in leaf sheaths of $A$. cepa Aggregatum group. In HPLC profiles both at 360 and $520 \mathrm{~nm}$, several peaks were observed in A. cepa Aggregatum group and AMAL with chromosome 5A from A. cepa Aggregatum group but no peak was observed in A. fistulosum and other AMALs. Four of the compounds observed at $360 \mathrm{~nm}$ were identified as known flavonoids, i.e., apigenin, kaempferol, quercetin, and rutin. Five out of the total 18 compounds at $520 \mathrm{~nm}$ were identified as known anthocyanins, i.e., cyanidin-3-glucoside, cyanidin-3-laminariobioside, peonidin-3glucoside, cyanidin-3-malonylglucoside, and cyanidin-3-malonyllaminariobioside. These results reveal that a group of the genes related to the flavonoid and anthocyanin production in the leaf sheath of A. cepa Aggregatum group are located on the chromosome 5A.
\end{abstract}

\section{INTRODUCTION}

A series of alien monosomic addition lines (AMALs) of Japanese bunching onion (Allium fistulosum L., genomes $\mathrm{FF}, 2 n=2 \mathrm{X}=16)$ having extra chromosomes $(1 \mathrm{~A}-8 \mathrm{~A})$ from shallot (A. cepa L. Aggregatum group, AA, $2 n=2 \mathrm{X}=16$ ) was established in our previous study (Shigyo et al., 1996). The chromosomal locations of 10 isozyme and one 5S rRNA genes were determined by isozyme and rDNA analyses using the series (Shigyo et al., 1994; Shigyo et al., 1995a; Shigyo et al., 1995b; Shigyo et al., 1996). These studies demonstrated that the series was useful to determine the chromosomal locations of genes and chromosome mapping of A. cepa Aggregatum group.

The results of a study on morphological characteristics in the series revealed that all the three plants of the AMAL with chromosome 5A from A. cepa Aggregatum group $(\mathrm{FF}+5 \mathrm{~A})$ showed reddish-yellow leaf sheaths (Shigyo et al., unpublished data). It seems that the genes related to the pigment production are obviously located on the chromosome 5A. The pigments were presumed to be flavonoids and anthocyanins, similarly produced in the skin of the

\footnotetext{
* Corresponding author.
}

bulbs of common onion (A. cepa L. Common onion group) (Fenwick and Hanley, 1990).

In the present study, the pigments produced in the leaf sheath of the AMAL FF + 5A were analyzed in detail using high-performance liquid chromatography (HPLC).

\section{MATERIALS AND METHODS}

A series of the AMALs of A. fistulosum possessing the extra chromosomes from A. cepa Aggregatum group $(\mathrm{FF}+1 \mathrm{~A}-\mathrm{FF}+8 \mathrm{~A})$ was used in the present study. Two plants were selected in each type of AMALs. A. fistulosum and A. cepa Aggregatum group were also used as controls.

The skin of the basal part of leaf sheath was collected from each plant material. The pieces of skin were lyophilized and cut, and 15-20 mg of them were extracted at room temperature with $0.5 \mathrm{ml}$ of methnol for $24 \mathrm{~h}$ for flavonoid and with $1 \mathrm{ml}$ of TMW (1\% trifluoroacetic acid in $80 \%$ methnol) for $48 \mathrm{~h}$ for anthocyanin. After filtrating with a millipore filter $(0.45 \mu \mathrm{m})$, the extract was injected into HPLC (2-5 $\mu \mathrm{l}$ for flavonoids, $20 \mu \mathrm{l}$ for anthocyanins).

HPLC apparatus were SHIMADZU LC-6A system with UV spectro-photo meter (SPD-6AV) for flavonoid analysis and HITACHI L-6200 pumping system with UV spectro- 

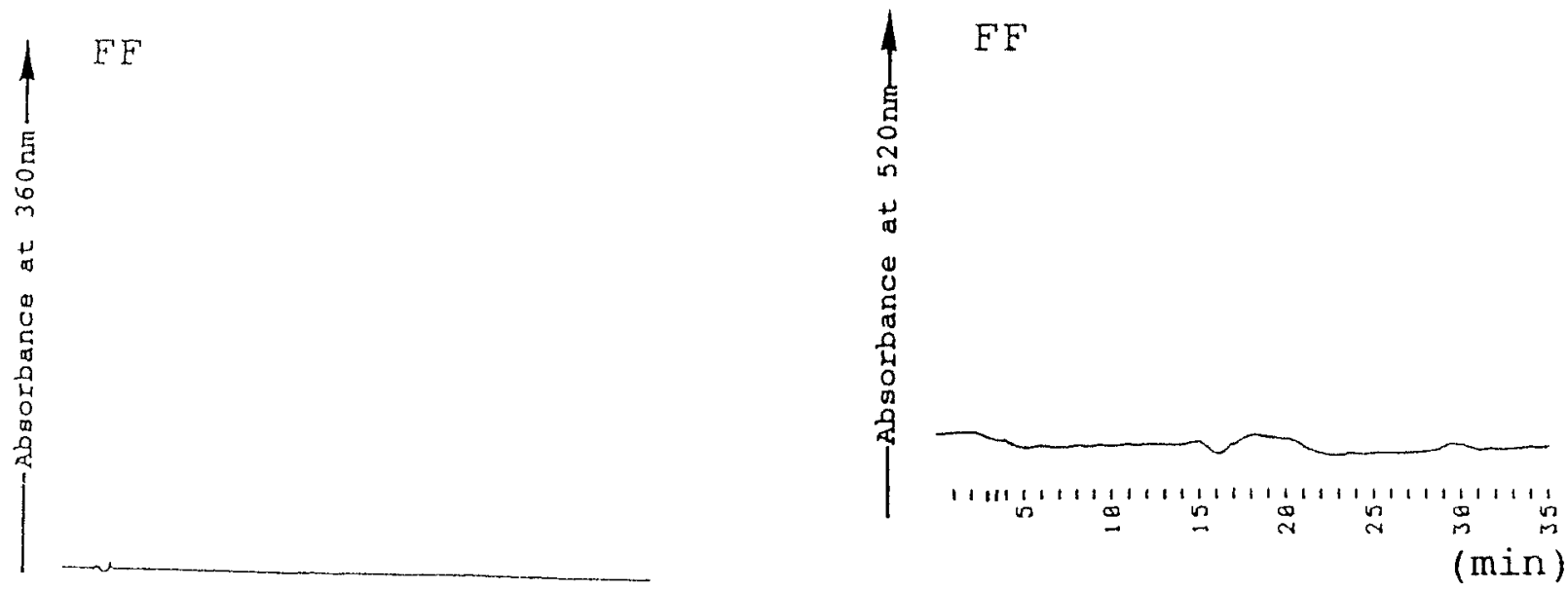

(min)
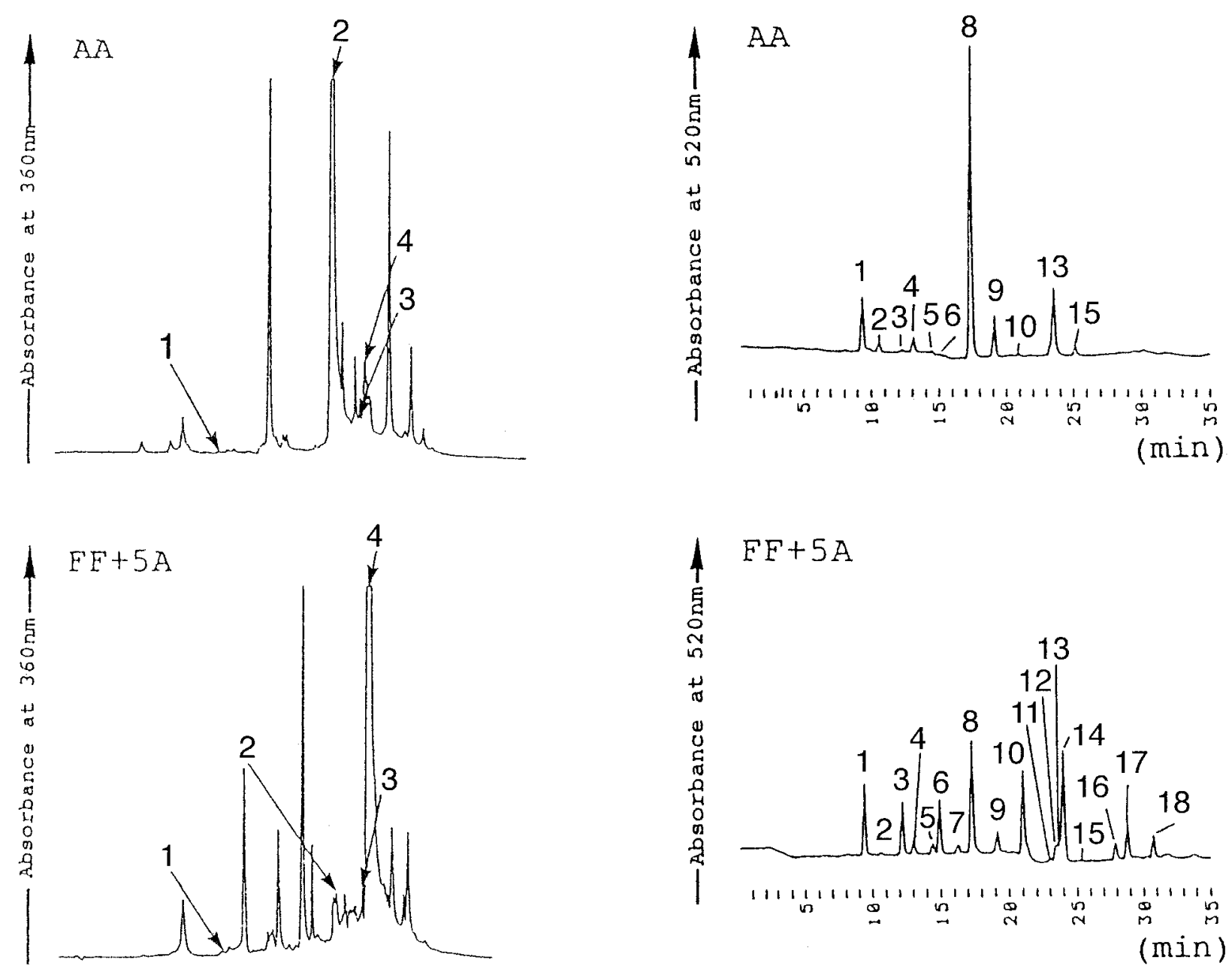

Fig. 1. HPLC profiles of methanol extracts of A. fistulosum, A. cepa Aggregatum group, and alien monosomic addition line $\mathrm{FF}+5 \mathrm{~A}$ (detection : $360 \mathrm{~nm}) .1$, rutin $(\mathrm{Rt}=14.9) ; 2$, quercetin $(\mathrm{Rt}=23.0)$; 3 , apigenin $(\mathrm{Rt}=25.0) ; 4$, kaempferol $(\mathrm{Rt}=25.4)$.

Fig. 2. HPLC profiles of TMW extracts of A. fistulosum, A. cepa Aggregatum group, and alien monosomic addition line $\mathrm{FF}+5 \mathrm{~A}$ (detection: $520 \mathrm{~nm})$. 1, cyanidin-3-glucoside (Cy3-Glc); 2, cyanidin3-laminariobioside (Cy3-Lam); 5, peonidin-3-glucoside (Pn3-Glc); 8, cyanidin-3-malonylglucoside(Cy3-MaGlc); 9, cyanidin-3malonyllaminariobioside (Cy3-MaLam). Other peaks, 3, 4, 6, 7, $10,11,12,13,14,15,16,17$, and 18 were not identified. 
photometer (SHIMADZU S-2000) for anthocyanin analysis. Analyses of flavonoids were carried out using a CAPCELL PAK C18 column $(4.6 \mathrm{~mm} \times 250 \mathrm{~mm})$ with 1 $\mathrm{mM}$ tetrabutylammonium (adjusted to $\mathrm{pH} 2.9$ with acetic acid) - acetonitrile $(9: 1 \rightarrow 1: 4$, in $32 \mathrm{~min})$ as the mobile phase, and monitored by the absorbance at $360 \mathrm{~nm}$. The flow rate was $0.6 \mathrm{ml} / \mathrm{min}$ throughout the analysis. The column temperature was $40^{\circ} \mathrm{C}$. The HPLC conditions for anthocyanin analyses were as follows: column, Inertsil ODS2 column $(4.6 \mathrm{~mm} \times 250 \mathrm{~mm})$; mobile phase, $1.5 \%$ phosphate $-1.5 \%$ phosphate, $20 \%$ acetic acid and $25 \%$ acetonitrile ( $3: 1 \rightarrow 2: 3$, in $35 \mathrm{~min}$ ); flow rate, $1 \mathrm{ml} / \mathrm{min}$; column temp., $35^{\circ} \mathrm{C}$; detect, $520 \mathrm{~nm}$.

The peaks obtained in the detection at $360 \mathrm{~nm}$ and 520 $\mathrm{nm}$ were respectively identified by comparisons of the retention time with that of standard compounds.

\section{RESULTS AND DISCUSSION}

In HPLC profile detected at $360 \mathrm{~nm}$, a large number of peaks attributable to flavonoids were observed in A. cepa Aggregatum group but no peak was observed in $A$. fistulosum (Fig. 1). Although a large number of peaks were also observed in two plants of AMAL FF $+5 \mathrm{~A}$, no peak was observed in any of other AMALs $(\mathrm{FF}+1 \mathrm{~A}, \mathrm{FF}+2 \mathrm{~A}, \mathrm{FF}+3 \mathrm{~A}$, $\mathrm{FF}+4 \mathrm{~A}, \mathrm{FF}+6 \mathrm{~A}, \mathrm{FF}+7 \mathrm{~A}$, and $\mathrm{FF}+8 \mathrm{~A})$. Four of the compounds observed at $360 \mathrm{~nm}$ were identified as known flavonoids, i.e., apigenin, kaempferol, quercetin, and rutin. These flavonoids were detected in all plants of $A$. cepa Aggregatum group and the AMAL FF +5A (Table 1). A fairly high content of kaempferol appeared in the AMAL $\mathrm{FF}+5 \mathrm{~A}$ but a low one in A. cepa Aggregatum group. Conversely, $\mathrm{FF}+5 \mathrm{~A}$ had a low content of quercetin but $A$. cepa Aggregatum group had a high one. The results revealed that the genes for the production of kaempferol were located on the chromosome 5A. Further, they also indicate that the kaempferol-3'-hydroxylase gene acting in the

Table 1. Flavonoid contents in A. fistulosum, A. cepa Aggregatum group, and alien monosomic addition lines (AMALs)

\begin{tabular}{lcrrrrr}
\hline \hline \multirow{2}{*}{ Flavoniod } & \multicolumn{7}{c}{ HPLC peak area / 1 mg-sample $(\mu \mathrm{v}$. sec $)$} \\
\cline { 2 - 7 } & FF 1, 2 & AA 1 & AA 2 & FF + 5A 1 & FF + 5A 2 & Other AMALs \\
\hline Apigenin & - & 3.5 & 20.7 & 13.3 & 16.8 & - \\
Kaempferol & - & 9.3 & 47.0 & 644.3 & 312.9 & - \\
Quercetin & - & 432.9 & 458.9 & 18.4 & 26.7 & - \\
Rutin & - & 0.4 & - & 0.9 & 0.4 & - \\
\hline
\end{tabular}

- , Not detectable.

Table 2. Anthocyanin contents in A. fistulosum, A. cepa Aggregatum group, and alien monosomic addition lines (AMALs)

\begin{tabular}{|c|c|c|c|c|c|c|c|c|}
\hline \multirow{2}{*}{$\begin{array}{l}\text { Peak } \\
\text { number }\end{array}$} & \multicolumn{6}{|c|}{ HPLC peak area / 1 mg-sample ( $\mu$ v. sec) } & \multirow{2}{*}{$\begin{array}{l}\text { Retention } \\
\text { time(min) }\end{array}$} & \multirow{2}{*}{ Anthocyanin $^{\mathrm{a}}$} \\
\hline & FF 1,2 & AA 1 & AA 2 & $\mathrm{FF}+5 \mathrm{~A} 1$ & $\mathrm{FF}+5 \mathrm{~A} 2$ & other AMALs & & \\
\hline 1 & - & 321 & 482 & 112 & 30 & - & 9.3 & Cy 3-Glc \\
\hline 2 & - & 59 & 68 & $\operatorname{tr}$ & $\operatorname{tr}$ & - & 10.5 & Cy 3-Lam \\
\hline 3 & - & 14 & 19 & 80 & 20 & - & 12.2 & \\
\hline 4 & - & 90 & 121 & 25 & 16 & - & 13.1 & \\
\hline 5 & - & 18 & 17 & 17 & 14 & - & 14.4 & Pn 3-Glc \\
\hline 6 & - & $\operatorname{tr}$ & 23 & 83 & 35 & - & 14.9 & \\
\hline 7 & - & - & - & 17 & $\operatorname{tr}$ & - & 16.3 & \\
\hline 8 & - & 1625 & 1965 & 175 & 69 & - & 17.3 & Cy 3-MaGlc \\
\hline 9 & - & 227 & 192 & 75 & 12 & - & 19.1 & Cy 3-MaLam \\
\hline 10 & - & 12 & 21 & 177 & 52 & - & 20.9 & \\
\hline 11 & - & - & - & tr & $\operatorname{tr}$ & - & 22.7 & \\
\hline 12 & - & - & - & $\mathrm{sh}$ & 39 & - & 22.9 & \\
\hline 13 & - & 449 & 625 & sh & - & - & 23.0 & \\
\hline 14 & - & - & - & 232 & 105 & - & 23.7 & \\
\hline 15 & - & 55 & 50 & $\operatorname{tr}$ & - & - & 25.0 & \\
\hline 16 & - & - & - & 29 & $\operatorname{tr}$ & - & 27.6 & \\
\hline 17 & - & - & - & 66 & 24 & - & 28.5 & \\
\hline 18 & - & - & - & 46 & 62 & - & 30.0 & \\
\hline
\end{tabular}

- , Not detectable.

tr, Trace.

sh, Shoulder.

a, See legend in Fig. 2. 
synthesis of quercetin is not on the chromosome 5A. A double monosomic alien chromosome addition lines of $A$. fistulosum with the chromosome 5A and with a chromosome other than $5 \mathrm{~A}(\mathrm{FF}+5 \mathrm{~A}+\mathrm{nA})$ will be useful to determine the chromosomal locations of the gene. There are several unidentified peaks in A. cepa Aggregatum group and in the AMAL FF + 5A. Identification of the compounds corresponding to the peaks will provide information necessary for determining the chromosomal locations of genes for the enzymes acting in the flavonoid biosynthetic pathway. It is also important to examine the effects of genes from A. fistulosum on the pigment production in the AMALs used in this study.

In the detections at $520 \mathrm{~nm}$, there was a tendency similar to those at $360 \mathrm{~nm}$; a large number of peaks were observed in A. cepa Aggregatum group and the AMAL FF + 5A (Fig. 2) but no peak was observed in A. fistulosum and any of other AMALs $(\mathrm{FF}+1 \mathrm{~A}, \mathrm{FF}+2 \mathrm{~A}, \mathrm{FF}+3 \mathrm{~A}, \mathrm{FF}+4 \mathrm{~A}$, $\mathrm{FF}+6 \mathrm{~A}, \mathrm{FF}+7 \mathrm{~A}$, and $\mathrm{FF}+8 \mathrm{~A})$. The AMAL FF + 5A had larger number of peaks than $A$. cepa Aggregatum group. The compounds peak nos. $7,11,12,14,16,17$, and 18 were detected only in the AMAL FF + 5A (Table 2). The peak nos. 1, 2, 5, 8, and 9 were identified as five different anthocyanins (Fig. 2). These results revealed that the genes for the anthocyanin production were also located on the chromosome 5A. Seven peaks were observed in the AMAL $\mathrm{FF}+5 \mathrm{~A}$ but not in A. cepa Aggregatum group, and several of which have not yet been characterized. If the structural determinations of the unknown compounds are completed, the chromosomal locations of genes for the enzymes in anthocyanin biosynthetic pathway will be determined.

From the results mentioned above, it is concluded that a group of the genes related to both the flavonoid and anthocyanin production in the leaf sheath of $A$. cepa Aggregatum group are located on the chromosome 5A. A concentra- tion of the genes related to both pigments production on one chromosome is a matter of great interest to trace the chromosomal evolution in Allium and is convenient to manipulate the genes. A large number of structural genes coding enzymes and regulatory genes seems to be involved in the pigment biosynthetic pathways. It will be possible to determine the chromosomal localization of these genes by means of the methods of molecular genetics in future.

The authors are grateful to S. Miyazaki of Saga University for his valuable suggestions and continuous encouragement. The research was supported in part by Grant-in-Aid for Research Fellow of the Japan Society for the Promotion of Science (No. 0058) from the Ministry of Education, Science, Sports, and Culture of Japan. M. S. is a research fellow of the Japan Society for the Promotion of Science.

\section{REFERENCES}

Fenwick, G. R. and Hanley, A. B. (1990) Chemical composition. In: Onions and Allied Crops Volume 3 (eds.: H. D. Rabinowitch and J. L. Brewster), pp. 17-31. CRC Press, Inc., Boca Raton, FL.

Shigyo, M., Tashiro, Y., and Miyazaki, S. (1994) Chromosomal locations of glutamate oxaloacetate transaminase gene loci in Japanese bunching onion (Allium fistulosum L.) and shallot (A. cepa L. Aggregatum group). Jpn. J. Genet. 69, 417-424.

Shigyo, M., Tashiro, Y., Isshiki, S., and Miyazaki, S. (1995a) Chromosomal locations of five isozyme gene loci (Lap-1, Got-1, 6Pgdh-2, Adh-1 and Gdh-1) in shallot (A. cepa L. Aggregatum group). Jpn. J. Genet. 70, 399-407.

Shigyo, M., Tashiro, Y., Isshiki, S., and Miyazaki, S. (1995b) Chromosomal locations of isocitrate dehydrogenase and phosphoglucoisomerase gene loci in shallot (A. cepa L. Aggregatum group). Jpn. J. Genet. 70, 627-632.

Shigyo, M., Tashiro, Y., Isshiki, S., and Miyazaki, S. (1996) Establishment of a series of alien monosomic addition lines of Japanese bunching onion (Allium fistulosum L.) with extra chromosomes from shallot (A. cepa L. Aggregatum group). Genes Genet. Syst. 71, 363-371. 